Sains Malaysiana 46(1)(2017): 107-116

http://dx.doi.org/10.17576/jsm-2017-4601-14

\title{
The HARX-GJR-GARCH skewed-t multipower realized volatility modelling for S\&P 500
}

(Pemodelan Kemeruapan Terealisasi Pelbagai-Kuasa HARX-GJR-GARCH terpencong- $t$ untuk S\&P 500)

\author{
Chin Wen CHEOnG*, LeE Min Cherng, NADiRA MoHAmed IsA \& PoO KuAn Hoong
}

\begin{abstract}
The heterogeneous autoregressive (HAR) models are used in modeling high frequency multipower realized volatility of the $S \& P 500$ index. Extended from the standard realized volatility, the multipower realized volatility representations have the advantage of handling the possible abrupt jumps by smoothing the consecutive volatility. In order to accommodate clustering volatility and asymmetric of multipower realized volatility, the HAR model is extended by the threshold autoregressive conditional heteroscedastic (GJR-GARCH) component. In addition, the innovations of the multipower realized volatility are characterized by the skewed student-t distributions. The extended model provides the best performing insample and out-of-sample forecast evaluations.
\end{abstract}

Keywords: GARCH; HAR; realized volatility

\section{ABSTRAK}

Model autoregresi heterogen (HAR) digunakan dalam pemodelan kemeruapan terealisasi pelbagai-kuasa untuk indeks S\&P500. Lanjutan daripada kemeruapan terealisasi piawai, kemeruapan pelbagai-kuasa mempunyai kelebihan menangani kemungkinan perubahan mendadak dengan pelicinan kemeruapan berturutan. Untuk permodelan kemeruapan kelompok dan tak simetri, model HAR dilanjutkan dengan komponen autoregresi heteroskedastik bersyarat ambang (GJRGARCH). Selain itu, inovasi kemeruapan terealisasi dicirikan dengan taburan student-t terpencong. Model lanjutan HAR memberi prestasi terbaik dalam penilaian penganggaran dan ramalan.

Kata kunci: GARCH; HAR; kemeruapan terealisasi

\section{INTRODUCTION}

Integrated volatility estimation based on high frequency data is one of the famous model-free measures of latent volatility, which normally cannot be directly observed from the raw daily financial data. The usage of high frequency daily data (Cervello et al. 2015; Cheong et al. 2016a, 2016b; Degiannakis \& Floros 2013; Inkaya \& Oku 2014; Wang et al. 2015; Zu \& Obswijk 2014) provides volatility estimates that have direct impact to the accuracy of portfolio investment and risk management. From the academician point of view, the presence of predictable volatility gives additional information in the efficiency market hypothesis analysis. One of the early high frequency data analyses in financial market was introduced by Andersen and Bollerslev (1998). They approximate the high frequency realized volatility (RV) to latent volatility which is related to the theory of quadratic variation and integrated variance. Consider a stochastic volatility process for logarithmic prices of a financial asset, $d p(t)=\mu(t) d t+\sigma(t) d w(t)$, where $\mu(t), \sigma(t)$ and $W(t)$ are the drift, volatility and standard Brownian motion, respectively. The $\mu(t)$ and $\sigma(t)$ may be time-varying but are assumed to be independent of $d W(t)$. Alternately, $p_{t}=p_{0}+$ $\int_{0}^{t} \mu(t) d t+\int_{0}^{t} \sigma(t) d W(t)$. The quadratic variation process for a sequence of partitions when $m$ approaches $\infty$ is equivalent to the integrated variance $\lim _{m \rightarrow \infty} \sum_{i=0}^{m-1}\left(p_{\tau_{i+1}}-p_{\tau_{p}}\right)^{2}=\int_{0}^{t} \sigma^{2}(t)$ $d t$. In other words, the quadratic variation and hence the integrated variance can be consistently estimated by the sum of squares returns.

In most of the finance applications, the continuously compounded intraday returns of day $T$ with sampling frequency $N$ can be written as $\tau_{t, j}=100\left(\ln P_{t, j}-\ln P_{t, j-1}\right)$, with $j=1, \ldots, N$ and $t=1, \ldots, T$. Thus, a full trading day for S\&P500 with six and a half hours consists of 785 min data. Andersen and Bollerslev (1998) aggregated the squared intraday returns and forms the realized volatility $(\mathrm{RV}), \sigma_{A B, t}^{2}=\sum_{j=1}^{N} \tau_{t, j}^{2}$. As the sampling frequency of intraday returns approaches infinity, the RV converges uniformly in probability (Barndorff-Nielsen \& Shephard 2002) to $\sigma_{A B, t}^{2} \rightarrow \int_{t-1}^{t} \sigma^{2}(t) d t$. It is noted that in the presence of abrupt jumps in the series, the RV is no longer consistent estimate for integrated variance. Thus, a more robust estimator which immunes to jump is needed to overcome this inconsistency issue. In order to capture high volatile financial markets with possible jumps, a general realized multipower $(p)$ variation estimator (Barndorff-Nielsen \& Shephard 2002) 
for latent volatility of the corresponding integrated power of the volatility is proposed as,

$$
M P V_{t}(i, p)=\mu_{p / i}^{-1}\left(\frac{t}{t-i+1}\right) t^{\frac{p}{2}-1} \sum_{j=1}^{t-i+1}\left|r_{j}\right|^{p / i} \ldots\left|r_{j+i-1}\right|^{p / i},
$$

where $n$ and $p$ are positive integers with the relationship $n>p / 2$ with a finite sample correction of $\left(\frac{t}{t-i+1}\right)$. The term $i$ normally sets the window size of return blocks and $p$ indicates the desired power variation. For i.i.d price changes, $\left.\mu_{p / i}=2^{\frac{p}{2 i}} \Gamma[p / i+1) / 2\right] / \Gamma[1 / 2]$. If all the adjacent returns are i.i.d normally distributed, Barndorff-Nielsen et al. (2006) claimed that each term of the $M P V$ delivers an unbiased estimate for the power of volatility. The power of the estimator can be altered by using specific values of $n$ and $p$, for example when $n=1$ and $p=2$, the estimator is referring to realized volatility proposed by Andersen et al. (2001) as $R V_{t}=M P V_{1, t}(i=1, p=2)=\mu_{2}^{-1} \sum_{j=1}^{t}\left|r_{j}\right|^{2}$. Other variation of estimators are such as Bipower variation volatility (Barndorff-Nielsen \& Shephard 2004), $B V_{t}=$ $M P V_{2, t}(i=2, p=2)=\mu_{1}^{-2} \frac{t}{t-1} \sum_{j=1}^{t-1}\left|r_{j}\right|\left|r_{j+1}\right|$, Tripower variation volatility (Andersen et al. 2006), $T V_{t}=M P V_{3, t}(i=3, p=$ 2) $=\mu_{2 / 3}^{-3} \frac{t}{t-2} \sum_{j=1}^{t-2}\left|r_{j+1}\right|^{2 / 3}\left|r_{j+2}\right|^{2 / 3}$ and Quadpower variation volatility (Barndorff-Nielsen \& Shephard 2004), $Q V_{t}=$ $M P V_{4, t}(i=4, p=2)=\mu_{1 / 2}^{-4} \frac{t}{t-3} \sum_{j=1}^{t-3}\left|r_{j}\right|^{1 / 2}\left|r_{j+1}\right|^{1 / 2}\left|r_{j+2}\right|^{1 / 2}\left|r_{j+3}\right|^{1 / 2}$. In general, the higher power variations smoothen the abrupt jumps by averaging to its adjacent(s) return(s).

The heterogeneous autoregressive (HAR) model (Corsi 2009; Corsi et al. 2008) is one of the famous high frequency models in finance applications. The HAR model specification is based on the concept of heterogeneous market hypothesis (Dacorogna et al. 2001; Muller et al. 1993). This hypothesis complements the traditional efficient market hypothesis (Fama 1998; Malkiel 2003) which assumes that the market participants are homogeneous in terms of market information and their ways of reacting to new market news. However, in the real situations, market participants interpreted the same market information differently according to their trading preferences and opportunities. In a more general way, their investment periods (Figure 1) can be categorized as short, medium and long where each of these different time horizon trading activities will create a unique volatility under the fluctuating price movements. These cascading volatilities are believed to generate long memory volatility in financial markets. Another popular counterpart namely the fractionally integrated (Andersen et al. 2006) ARMA models are not included in this study due to its finance interpretation issue.

In this present study, a HARX model is extended to accommodate for asymmetry volatility clustering as well as asymmetric relation between RV and volatility of RV. Besides the commonly used RV, we also include other alternative RVs which are robust to jumps such as bipower, tripower and quadpower variation volatility in the HAR models. In addition, the RV's errors are considered as leptokurtic and asymmetrically distributed which follow a skewed student- $t$ distribution. The extended new model framework is named as HARX (MPV)-GJR-GARCH skewed- $t$ model and is applied on the S\&P 500 index. As a comparison with the original models, the new model specification provides better in-sample as well as out-ofsample forecast evaluations. Therefore, the higher power jump-robust volatilities should be taken into account in the volatility model specification. To complete this study, we illustrate a one-day-ahead value-at-risk determination using the forecasted results.

The remaining of this manuscript is organized as follows: Next, we provides the description of multipower variation of volatility estimators, ARFIMA and HAR models; After that, we discusses the empirical data and results and finally, we concludes the findings of the study.

\section{METHODS}

THE HARX (MPV)-GJR-GARCH SKEWED-T MODEL

The basic HAR model proposed by Corsi (2009) constructed an additive hierarchical structure of various frequency realized volatilities according to daily, weekly and monthly

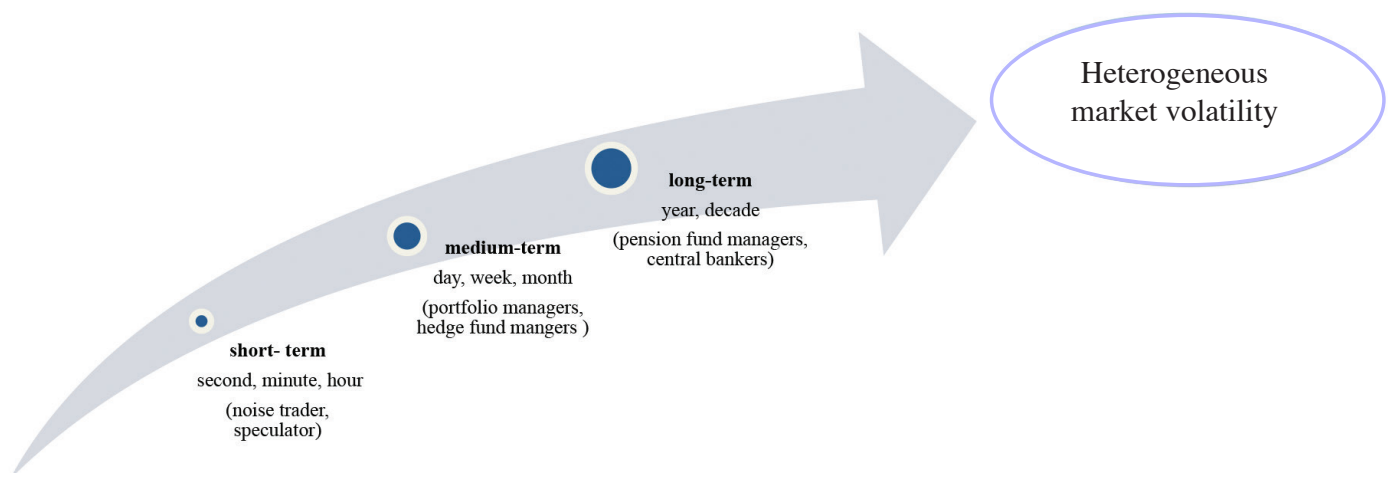

FIGURE 1. Structure of heterogeneous market's volatility 
volatility. In this study, we extended the HAR by including various power realized volatility under the specification of Barndorff-Nielsen and Shephard (2004). In addition, the innovations of the realized volatility are assumed to be leptokurtically and asymmetrically following a skewed student- $t$ distribution. Specifically, the HARX(MPV)-GJRGARCH(1,1)-skewed- $t$ model can be written as:

$$
\begin{aligned}
\ln \left(M P V_{i, t}^{d}\right)= & \theta_{i, 0}+\theta_{i, 1}\left|r_{t}\right| I_{t}\left(r_{t}<0\right)+\theta_{i, d} \ln \left(M P V_{i, t-1}^{\text {day }}\right)+ \\
& \theta_{i, w} \ln \left(M P V_{i, t-1}^{\text {week }}\right)+\theta_{i, m} \ln \left(M P V_{i, t-1}^{\text {month }}\right)+a_{i, a t} \\
a_{i t}= & \sigma_{\ln (M P V)_{i},} \varepsilon_{i, t} \\
\sigma_{\ln (M P V)_{i}, t}^{2}= & \alpha_{i, 0}+\alpha_{i, 1} a_{i, t-1}^{2}+\alpha_{i, 2}\left|a_{i, t}^{2}\right| I_{t}\left(a_{i, t}<0\right)+ \\
& \alpha_{i, 3} \sigma_{\ln (M P V)_{i}, t-1}^{2},
\end{aligned}
$$

where $M P V$ represents the type of realized volatility with $M P V_{t}^{\text {week }}=\frac{1}{5} \sum_{j=1}^{5} M P V_{t-j}^{\text {day }}$ and $M P V_{t}^{\text {month }}=\frac{1}{22} \sum_{j=1}^{22} M P V_{t-j}^{\text {day }}$. The term $\alpha_{2}$, captures the asymmetric behavior of realized volatility and $I_{t}($.$) is an identity function. For instance,$ when $\alpha_{2}>0$, negative (positive) news contribute to greater (smaller) magnitude of MPV. The GJR threshold (Glosten et al. 1993) specification is originally meant for capturing leverage effect in finance under the conditional mean and conditional volatility modelling. However, in this study, this specification is to explore the relationship between various realized volatility and its volatility. Next, the $X$ indicates whether the risk-premium (risk-return tradeoff) exists in the studied time series. The returns are expected to be positively correlated to the intensity of market volatility or risk. In other words, higher risk asset should offered higher returns in order investor to hold it.

For leptokurtic and asymmetrically distributed error series (Lambert \& Laurent 2001), $\varepsilon_{i, t} \mid \Omega_{t-1} \sim$ skew $-t(0,1$; $v, k)$, the density function is

$$
f\left(\varepsilon_{i, t} ; v, k\right)=\left\{\begin{array}{l}
\frac{\Gamma\left[\frac{v+1}{2}\right]}{\Gamma\left[\frac{v}{2}\right] \sqrt{\pi(v-2)}}\left(\frac{2 s}{k+k^{-1}}\right)\left(1+\frac{s \varepsilon_{i, t}+m}{v-2} k\right)^{-\left(\frac{v+1}{2}\right)} \quad \text { if } \varepsilon_{i, t}<-m s^{-1} \\
\frac{\Gamma\left[\frac{v+1}{2}\right]}{\Gamma\left[\frac{v}{2}\right] \sqrt{\pi(v-2)}}\left(\frac{2 s}{k+k^{-1}}\right)\left(1+\frac{s \varepsilon_{i, t}+m}{v-2} k\right)^{-\left(\frac{v+1}{2}\right)} \quad \text { if } \varepsilon_{i, t} \geq-m s^{-1}
\end{array},\right.
$$

with $v$ and $k$ are the tail and asymmetry parameters, respectively, where $s=\sqrt{k^{2}+k^{-2}-m^{2}-1}$ and $m=$ $\frac{k-k^{-1}}{\Gamma\left\{\left[\left(\frac{v-1}{2}\right)\right] \sqrt{v-2} \Gamma\left[\frac{v}{2}\right] \sqrt{\pi}\right\}}$. Overall, the vector parameters to be estimated are $\hat{\Theta}(\boldsymbol{\theta}, \boldsymbol{\alpha}, v, k)$ where $\boldsymbol{\theta}=\left(\theta_{0}, \theta_{1}, \theta_{d}, \theta_{w}, \theta_{m}\right)$ and $\boldsymbol{\alpha}=\left(\alpha_{0}, \alpha_{1}, \alpha_{2}, \alpha_{3}\right)$ Using the Ox-G@RCH, the estimations are conducted using the simulated annealing maximum likelihood (MaxSA) due to possibility of more than one local extrema which are also may not be smoothen.

The out-of-sample forecast evaluations are based on a rolling fixed sample size of $\mathrm{T}=1246$ for $h=1,2, \ldots$,
$H$ where $H$ is fixed as 100 . The various one-day-ahead logarithmic realized volatility forecasts are computed as follows:

$$
\begin{aligned}
& \ln \left(M P V_{i, t+1}^{d}\right)=\theta_{i, 0}+\theta_{i, 1}\left|r_{t+1}\right| l_{t+1}\left(r_{t+1}<0\right)+ \\
& \theta_{i, d} \ln \left(M P V_{i, t}^{\text {day }}\right)+\theta_{i, w} \ln \left(M P V_{i, t}^{\text {week }}\right)+ \\
& \theta_{i, m} \ln \left(M P V_{i, t}^{\text {month }}\right)+a_{i, t+1} \\
& \sigma_{\ln (M P V)_{i} t+1}^{2}=\alpha_{i, 0}+\alpha_{i, 1} a_{i, t}^{2}+\alpha_{i, 2}\left|a_{i, t+1}^{2}\right| l_{t}\left(a_{i, t+1}<0\right)+\alpha_{i, 3} \sigma_{\ln (M P V)_{i} t}^{2} \text {, }
\end{aligned}
$$

where $R V_{t}^{\text {week }}=\frac{1}{5} \sum_{j=1}^{5} \ln \left(R V_{t-j+1}^{d a y}\right)$ and $R V_{t}^{\text {month }}=\frac{1}{22} \sum_{j=1}^{22} \ln$ $\left(R V_{t-j+1}^{d a y}\right)$. Thus, the vector $\hat{\Theta}^{(t)}\left(\boldsymbol{\theta}^{(t)}, \boldsymbol{\alpha}^{(t)}, v^{(t)}, k^{(t)}\right)$ is re-estimated every day for $t=h, h+1, \ldots, h+T$-1 days. For out-of-sample forecast evaluations, four measurements namely the mean squared error (MSE $\left.=\frac{1}{H} \sum_{h=t+1}^{t+H}\left(\sigma_{\text {Actual }, h}^{2}-\sigma_{\text {Forecas }, h}^{2}\right)^{2}\right)$ and its corresponding heteroscedasticity adjusted statistic HMSE $\left(\right.$ HMSE $\left.=\frac{1}{H} \sum_{h=t+1}^{t+H}\left(1-\frac{\sigma_{\text {actual }, h}^{2}}{\sigma_{\text {forecast }, h}^{2}}\right)^{2}\right)$, mean absolute error (MAE $\left.=\frac{1}{H} \sum_{h=t+1}^{t+H}\left(\sigma_{\text {Actual }, h}^{2}-\sigma_{\text {Forecast }, h}^{2}\right)\right)$ and its corresponding HMAE $\left(\right.$ HMAE $=\frac{1}{H} \sum_{h=t+1}^{t+H}\left(1-\frac{\sigma_{\text {actual }, h}^{2}}{\sigma_{\text {forecas }, h}^{2}}\right)$ ) are selected for this study. For HMSE and HMAE, both are able to accommodate the heteroscedasticity (Bollerslev \& Ghysels 1996) in the forecast errors. In this study, we focus on these four basic measurements which based directly on the deviation between forecasts and realizations. The robustness of the forecast evaluations is based on the definition by Patton (2011) where the model ranking should be consistent no matter what types of proxies are being used in the forecast evaluations.

\section{EMPIRICAL STUDY FOR S\&P 500}

The S\&P 500 index which serves as a barometer for U.S. economic has been selected for this study. Due to the high speculated market conditions during the sub-prime mortgage crisis, this index provides a good testbed for high volatile market analysis. The collected high frequency data from Bloomberg database consists of $1246\left(1^{\text {st }}\right.$ Feb 2008 until $31^{\text {st }}$ January 2013) intraday observations whereas intraday data starts from $1^{\text {st }}$ Feb 2013 to $30^{\text {th }}$ Jul 2013 are reserved for out-of-sample forecast evaluations. Figure 2 illustrates high intensity volatility compared to the others during the period from year 2008 to year 2009 with a continuously plunge ended in February 2009. Table 1 shows a quick glance on the descriptive statistics of all the logarithm power realized volatilities.

All the kurtosis and skewness are deviated from three and greater than zero, which indicates that the presence of non-gaussianity properties in all the series. Graphically, the non-gaussianity can also be observed from their density 


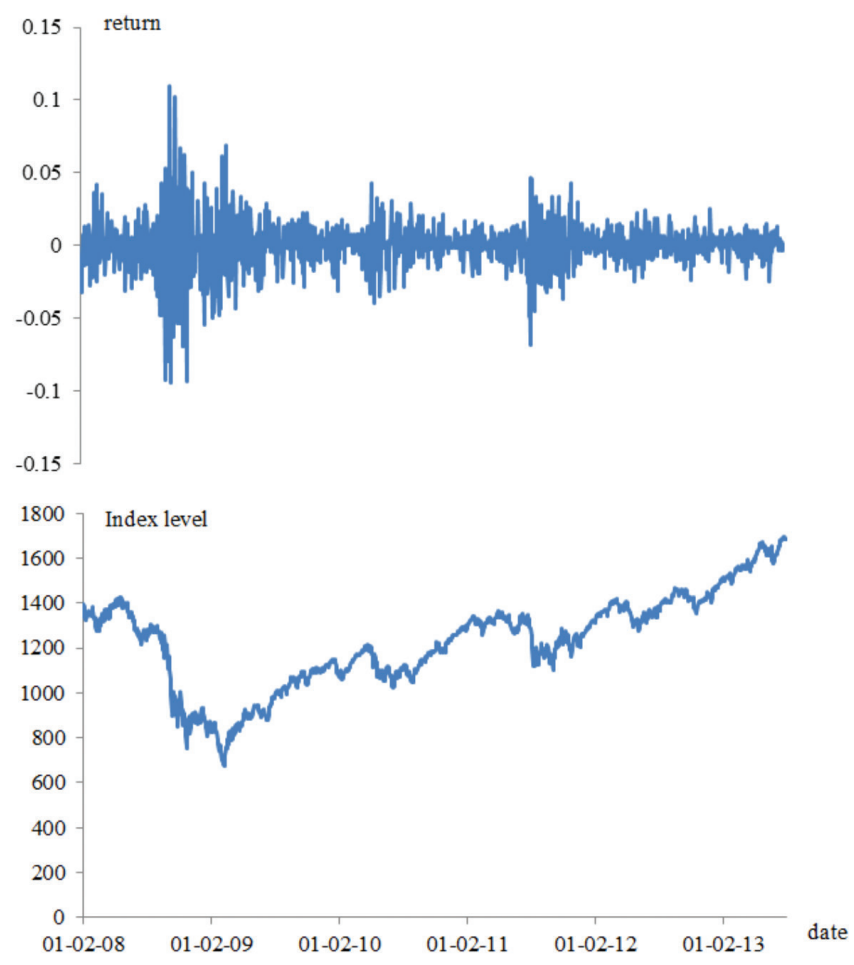

FIGURE 2. Index level and return series for S\&P 500

TABLE 1. Descriptive statistics for logarithm multipower variation of realized volatility

\begin{tabular}{lcccc}
\hline & $\operatorname{Ln}(\mathrm{RV})$ & $\operatorname{Ln}(\mathrm{BV})$ & $\operatorname{Ln}(\mathrm{TV})$ & $\operatorname{Ln}(\mathrm{QV})$ \\
\hline Mean & -9.179536 & -9.548012 & -9.624427 & -9.663881 \\
Median & -9.293311 & -9.652443 & -9.739006 & -9.786752 \\
Maximum & -4.788000 & -5.233757 & -5.177746 & -5.188110 \\
Minimum & -12.10241 & -12.33713 & -12.49701 & -12.68837 \\
Std. Dev. & 1.165273 & 1.125177 & 1.139515 & 1.150303 \\
Skewness & 0.559742 & 0.698988 & 0.709102 & 0.695196 \\
Kurtosis & 3.300867 & 3.516373 & 3.587237 & 3.568282 \\
Jarque-Bera & $69.70793 *$ & $115.2134 *$ & $122.2253^{*}$ & $117.0370 *$ \\
\hline
\end{tabular}

* indicate $5 \%$ level of significance

plots in Figure 3 with slightly skewed to right especially for $\mathrm{BV}, \mathrm{TV}$ and $\mathrm{QV}$. Under the null hypothesis of a normal distribution, the Jacque-Bera statistics rejected all the series at the 5\% significance level. Using the quantilequantile plots with normal distribution versus logarithmic series, the positive skewness is indicated in all series. To summarize, the multipower variation volatility series have slightly higher peak (leptokurtic) and positively skewed when comparing to a normal distribution. Thus, one should include these distribution behaviors in the model specifications for in-sample and out-of-sample analyses.

\section{IN-SAMPLE FORECAST EVALUATIONS}

Tables 2 and 3 reports the overall 8 HAR-GJR-GARCH normal and HAR-GARCH(GJR) skewed- $t$ models under the 4 multipower variation volatility representations.
Due to the leptokurtic and positive skewed volatility, the constructions of normal distributed models are for the purpose of comparisons. The in-sample forecasts of HARGJR-GARCH skewed-t models shows that the heterogeneous autoregressive components $\left(\theta_{d a y}, \theta_{\text {week }}\right.$ and $\left.\theta_{\text {month }}\right)$ for daily, weekly and monthly volatilities are all significantly different from zero at 5\% level of significance. In other words, this findings support the presence of heterogeneous market hypothesis where the markets consist of non-homogeneous market participants with different time horizon investments preferences. For the risk premium (risk-return tradeoff) coefficient, $\theta_{l}$, all of them indicated positive correlation between the volatility and the negatively expected return (since the logarithmic volatility is in negative values). This shows that the higher risk market should offered higher return in order for the investors to hold it. For negatively 

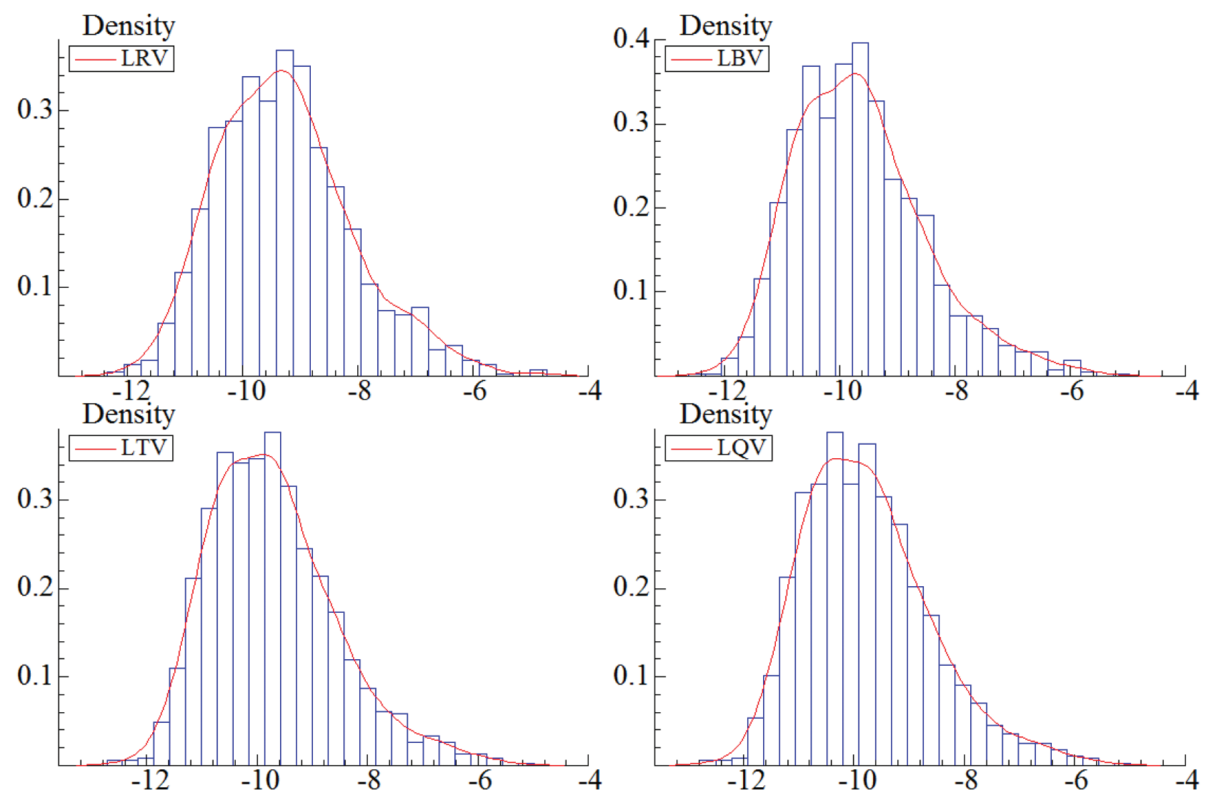

FIGURE 3. Density plots for all volatility logarithmic series
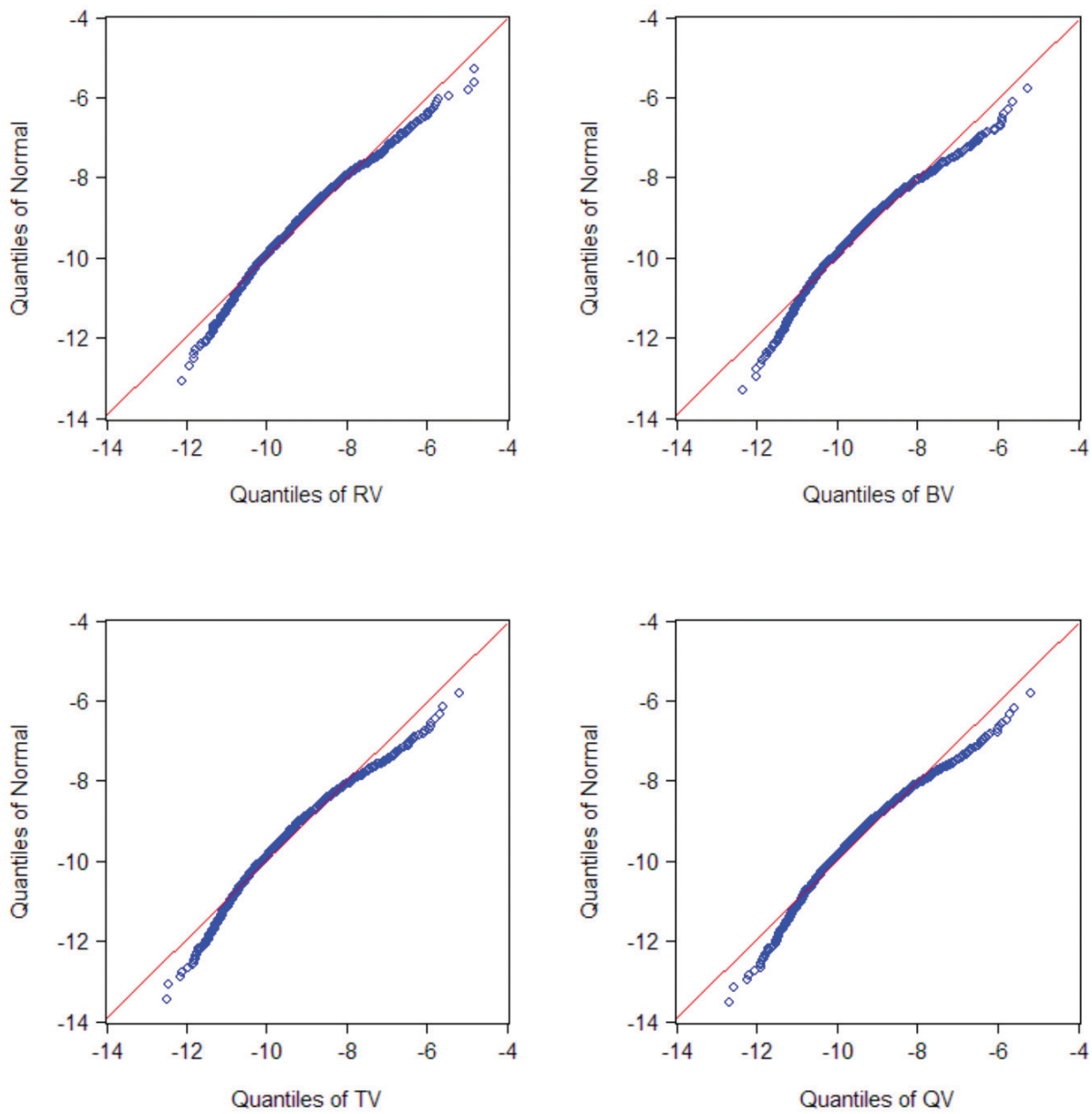

FIGURE 4. Quantile-quantile plots for all volatility series 
TABLE 2. The maximum likelihood estimation -skewed- $t$

\begin{tabular}{|c|c|c|c|c|}
\hline & $\sigma_{t}^{2}(\mathrm{RV})$ & $\sigma_{t}^{2}(\mathrm{BV})$ & $\sigma_{t}^{2}(\mathrm{TV})$ & $\sigma_{t}^{2}(\mathrm{QV})$ \\
\hline$\theta_{0}$ & $-1.237847^{* * *}(0.2014)$ & $-0.801015^{* *}(0.21898)$ & $-0.401417^{* *}(0.00007)$ & $-0.767258^{* *}(0.2359)$ \\
\hline$\theta_{1 \text { (risk premium) }}$ & $-20.388240^{* *}(2.3781)$ & $-11.407904^{* *}(1.9759)$ & $-5.099477^{* *}(0.00014)$ & $-9.246969^{* *}(1.9689)$ \\
\hline$\theta_{d a y, t-1}$ & $0.115569^{* *}(0.0347)$ & $0.287488^{* *}(0.0360)$ & $0.457625^{* *}(0.00011)$ & $0.352058^{* *}(0.0358)$ \\
\hline$\theta_{\text {week }, t-1}$ & $0.521662^{* *}(0.0586)$ & $0.676784^{* *}(0.0567)$ & $0.446479^{* *}(0.00012)$ & $0.631021^{* *}(0.0618)$ \\
\hline$\theta_{\text {month }, t-1}$ & $0.239185^{* *}(0.0499)$ & $0.246643^{* *}(0.0583)$ & $0.517134^{* *}(0.00016)$ & $0.296063^{* *}(0.0632)$ \\
\hline$\alpha_{0}$ & $0.035660^{*}(0.0214)$ & $0.015005^{* *}(0.0073)$ & $0.089316^{* *}(0.00003)$ & $0.019526(0.0127)$ \\
\hline$\alpha_{1}$ & $0.160797^{* *}(0.0435)$ & $0.077164^{* *}(0.0227)$ & $0.081433^{* *}(0.00025)$ & $0.069964^{* *}(0.0246)$ \\
\hline$\alpha_{2 \text { (asymmetry) }}$ & $-0.037417(0.0424)$ & $-0.071589^{* *}(0.0283)$ & $-0.125841^{* *}(0.00025)$ & $-0.073159^{* *}(0.0415)$ \\
\hline$\alpha_{3}$ & $0.780368^{* *}(0.0777)$ & $0.895601^{* *}(0.0369)$ & $0.612849^{* *}(0.00005)$ & $0.887540^{* *}(0.0517)$ \\
\hline$k_{\text {(Skewed) }}$ & $0.267734^{* *}(0.0496)$ & $0.102430^{* *}(0.0438)$ & $0.146072^{* *}(0.04021)$ & $0.119745^{* *}(0.0418)$ \\
\hline$v_{\text {(Heavy tail) }}$ & $14.025081^{* *}(6.5877)$ & $\left.12.402808^{* * *} 4.0643\right)$ & $8.573086^{* *}(3.2731)$ & $8.454018^{* *}(1.9025)$ \\
\hline \multicolumn{5}{|l|}{ Model selection } \\
\hline AIC & 1.875761 & 1.397890 & 1.385101 & 1.425864 \\
\hline SIC & 1.875607 & 1.397736 & 1.384947 & 1.425710 \\
\hline HIC & 1.921029 & 1.443159 & 1.430370 & 1.471132 \\
\hline \multicolumn{5}{|l|}{ Diagnostic } \\
\hline$\tilde{a}_{t}, \mathrm{LB}(10)$ & $17.9314^{*}[0.0561]$ & $11.4637[0.2452]$ & $10.1493[0.3385]$ & $11.2453[0.2592]$ \\
\hline$\tilde{a}_{t}^{2}, \mathrm{LB}(10)$ & $2.63523[0.9551]$ & $6.89709[0.5477]$ & $7.44431[0.4895]$ & $6.19657[0.6252]$ \\
\hline $\mathrm{ARCH}(10)$ & $0.25471[0.9901]$ & $0.66481[0.7579]$ & 0.68532 [0.7389] & $0.57340[0.8367]$ \\
\hline
\end{tabular}

Standard errors and $\mathrm{p}$-values are reported in round and square parentheses.

$* *$ and $*$ indicate $1 \%$ and $5 \%$ level of significance respectively.

TABLE 3. The maximum likelihood estimation -normal

\begin{tabular}{|c|c|c|c|c|}
\hline & $\sigma_{t}^{2}(\mathrm{RV})$ & $\sigma_{t}^{2}(\mathrm{BV})$ & $\sigma_{t}^{2}(\mathrm{TV})$ & $\sigma_{t}^{2}(\mathrm{QV})$ \\
\hline$\theta_{0}$ & $-1.404214^{* *}(0.2244)$ & $-0.924779^{* *}(0.2381)$ & $-0.914593^{* *}(0.2479)$ & $-0.908398^{* *}(0.2601)$ \\
\hline$\theta_{1 \text { (risk premium) }}$ & $-20.996265^{* *}(2.2535)$ & $-11.845286^{* *}(2.0760)$ & $-9.942112^{* *}(1.9545)$ & $-9.731292 * *(2.0460)$ \\
\hline$\theta_{d a y, t-1}$ & $0.131880^{* *}(0.0368)$ & $0.288744^{* *}(0.0387)$ & $0.329304^{* *}(0.0351)$ & $0.335515^{* *}(0.0361)$ \\
\hline$\theta_{\text {week }, t-1}$ & $0.484890^{* *}(0.0753)$ & $0.639780^{* *}(0.0598)$ & $0.692556^{* *}(0.0566)$ & $0.676587^{* *}(0.0582)$ \\
\hline$\theta_{\text {month, } t-1}$ & $0.241310^{* *}(0.0538)$ & $0.270983^{* *}(0.0631)$ & $0.218729^{* *}(0.0596)$ & $0.235818^{* *}(0.0620)$ \\
\hline$\alpha_{0}$ & $0.024759^{* *}(0.0182)$ & $0.013406(0.0094)$ & $0.016369(0.0123)$ & $0.018116(0.0147)$ \\
\hline$\alpha_{1}$ & $0.107518^{* *}(0.0411)$ & $0.065717^{* *}(0.0248)$ & $0.065536^{* *}(0.0263)$ & $0.061370^{* *}(0.0262)$ \\
\hline$\alpha_{2 \text { (asymmetry) }}$ & $0.011312^{* *}(0.0564)$ & $-0.060505^{* *}(0.0287)$ & $-0.065597^{*}(0.0378)$ & $-0.067333^{* *}(0.0399)$ \\
\hline$\alpha_{3}$ & $0.834785^{* *}(0.0639)$ & $0.908179^{* *}(0.0484)$ & $0.897987^{* *}(0.0568)$ & $0.898567^{* *}(0.0633)$ \\
\hline \multicolumn{5}{|c|}{ Model selection } \\
\hline AIC & 1.937123 & 1.414698 & 1.414587 & 1.455772 \\
\hline SIC & 1.937020 & 1.414595 & 1.414483 & 1.455669 \\
\hline $\mathrm{HIC}$ & 1.974161 & 1.451736 & 1.451625 & 1.492810 \\
\hline \multicolumn{5}{|l|}{ Diagnostic } \\
\hline$\tilde{a}_{t}, \mathrm{LB}(10)$ & $20.6345[0.0237]^{*}$ & $11.6767[0.2321]$ & $10.8156[0.2885]$ & 11.4944 [0.2433] \\
\hline$\tilde{a}_{t}^{2}, \mathrm{LB}(10)$ & $3.41750[0.9054]$ & $7.38367[0.4958]$ & $7.59401[0.4740]$ & 6.24982 [0.6192] \\
\hline $\mathrm{ARCH}(10)$ & 0.33780 [0.9709] & $0.71385[0.7121]$ & $0.69935[0.7258]$ & 0.57928 [0.8319] \\
\hline
\end{tabular}

Standard errors and p-values are reported in round and square parentheses.

$* *$ and $*$ indicate $1 \%$ and $5 \%$ level of significance, respectively 
asymmetric volatility for realized volatility, the coefficients $\alpha_{2}$, are all significant at $5 \%$ level of significance. Therefore, it is necessary to consider the GJR-GARCH modeling for volatility of multipower variation volatility. For skewness of the multipower variation volatility innovations, the coefficient $k s$ are all positively skewed. For the peakness of the innovations, all the tail parameters, $v$ s exhibited fatter tails than normal distribution. In other words, the innovations are leptokurtic and positively skewed than a standardized normal distribution.

For the diagnostic section, all the models failed to reject the Ljung-Box serial correlations for standardized and squared standardized innovations under the null hypothesis of serially uncorrelated series. However, only the RV-model for both HAR-GJR-GARCH normal and skewed- $t$ are rejected at $10 \%$ and $5 \%$ level of significance, respectively, for standardized innovations. This indicated that the RV representation does not fully statistically fit well in the introduced models. The misspecification may cause by the noisy data. On the other hand, the BV, TV and QV models fit well in the model specification tests under the multipower variation volatility specification. For model selection, overall the HAR-GJR-GARCH skewed- $t$ models are outperforming the normally distributed models for the same volatility representation. There is a great improvement in terms of information criteria (AIC, BIC and SIC) when shifted from RV to BV, TV and QV. In short, the jump-robust realized volatility representations are out-performing the standard realized volatility in the in- sample forecast evaluations. However, good out-of-sample forecasts (Hong et al. 2004) are affected by factors such as over-parameterization issue and unforeseen structural changes in the series.

\section{OUT-OF-SAMPLE FORECAST EVALUATIONS}

In order to provide an objective out-of-sample forecasts evaluation, the latent volatility is alternately represented by RV, BV, TV and QV. Overall there are four models under the model specifications of HAR (MPV)-GJR-GARCH skewed-t are evaluated by MSE, MAE, HMSE and HMAE, respectively. The out-of-sample 100 one-ahead forecasts are based on a rolling sample of 1246 trading days. Each estimated parameter vector $\widehat{\Theta}^{(t)}\left(\boldsymbol{\theta}^{(t)}, \boldsymbol{\alpha}^{(t)}, v^{(t)}, k^{(t)}\right)$ is re-estimated every day for 100 one-day-ahead forecasts. A simple scoring approach is used by granting 4 points for the best model and 1 point for the worst model. The score under the four different volatility proxies will be added to a final score for the ranking purposes. Table 4 and Figure 5 reports the forecast evaluations and plots for all the MPV models.

Overall, the higher power variation volatilities (BV, TV and QV) have shown better scores except when the RV acted as the proxy for latent volatility. This is an expected outcome because the RV series has much more noises than $\mathrm{BV}, \mathrm{TV}$ and $\mathrm{QV}$ where an averaging process has been implemented on the accumulated consecutive returns. This can also be observed from the higher standard

TABLE 4. Forecast evaluations

\begin{tabular}{|c|c|c|c|c|c|c|c|c|c|}
\hline \multirow{2}{*}{ Actual } & \multicolumn{8}{|c|}{ HAR(MPV)-GJR-GARCH skewed-t model } & \multirow[b]{2}{*}{ score } \\
\hline & MPV: & RV & score & BV & score & TV & score & QV & \\
\hline \multirow{5}{*}{$\begin{array}{l}\mathrm{RV} \\
\mathrm{BV} \\
\mathrm{TV} \\
\mathrm{QV}\end{array}$} & $M S E$ & 0.47430 & 4 & 0.64908 & 3 & 0.70417 & 2 & 0.75028 & 1 \\
\hline & $M S E$ & 0.45173 & 1 & 0.37223 & 4 & 0.37337 & 3 & 0.38664 & 2 \\
\hline & $M S E$ & 0.49255 & 1 & 0.34551 & 2 & 0.32659 & 4 & 0.33034 & 3 \\
\hline & $M S E$ & 0.54280 & 1 & 0.37056 & 1 & 0.34552 & 4 & 0.34568 & 2 \\
\hline & Rank & (4) & 7 & (2) & 10 & (1) & 13 & (3) & 8 \\
\hline \multirow{5}{*}{$\begin{array}{l}\text { RV } \\
\text { BV } \\
\text { TV } \\
\text { QV }\end{array}$} & $M A E$ & 0.52950 & 4 & 0.64381 & 3 & 0.66754 & 2 & 0.69297 & 1 \\
\hline & $M A E$ & 0.54231 & 1 & 0.48244 & 3 & 0.47401 & 4 & 0.48342 & 2 \\
\hline & $M A E$ & 0.58042 & 1 & 0.46486 & 2 & 0.44900 & 4 & 0.45441 & 3 \\
\hline & $M A E$ & 0.61350 & 1 & 0.48887 & 2 & 0.46648 & 3 & 0.46526 & 4 \\
\hline & Rank & (4) & 7 & (2) & 10 & (1) & 13 & (2) & 10 \\
\hline \multirow{5}{*}{$\begin{array}{l}\text { RV } \\
\text { BV } \\
\text { TV } \\
\text { QV }\end{array}$} & HMSE & 0.00466 & 4 & 0.00591 & 3 & 0.00629 & 2 & 0.00666 & 1 \\
\hline & $H M S E$ & 0.00443 & 1 & 0.00339 & 3 & 0.00333 & 4 & 0.00342 & 2 \\
\hline & $H M S E$ & 0.00481 & 1 & 0.00315 & 2 & 0.00291 & 4 & 0.00292 & 3 \\
\hline & $H M S E$ & 0.00530 & 1 & 0.00338 & 2 & 0.00308 & 3 & 0.00306 & 4 \\
\hline & Rank & (4) & 7 & (2) & 10 & (1) & 13 & (2) & 10 \\
\hline \multirow{5}{*}{$\begin{array}{l}\text { RV } \\
\text { BV } \\
\text { TV } \\
\text { QV }\end{array}$} & $H M A E$ & 0.05243 & 4 & 0.06143 & 3 & 0.06308 & 2 & 0.06520 & 1 \\
\hline & $H M A E$ & 0.05353 & 1 & 0.04597 & 2 & 0.04470 & 4 & 0.04541 & 3 \\
\hline & $H M A E$ & 0.05722 & 1 & 0.04425 & 2 & 0.04230 & 4 & 0.04265 & 3 \\
\hline & HMAE & 0.06050 & 1 & 0.04656 & 2 & 0.04396 & 3 & 0.04366 & 4 \\
\hline & Rank & (4) & 7 & (3) & 9 & (1) & 13 & (2) & 11 \\
\hline
\end{tabular}

Note: The highest and lowest score are 4 and 1 respectively 

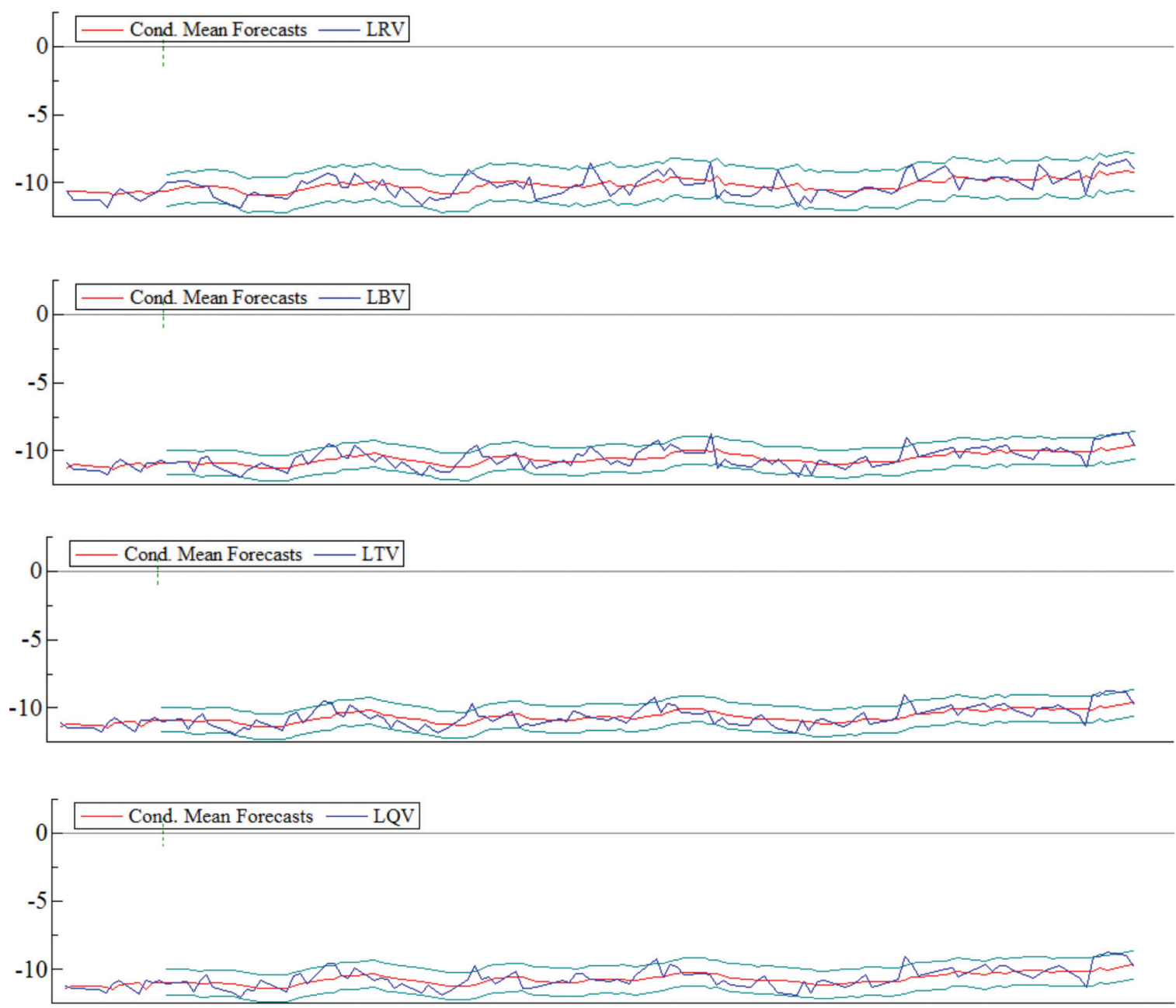

FIGURE 5. 100 one-day-ahead Forecasts for multipower variation volatility

deviation of RV in Table 1 descriptive statistics. The TV has outperformed other models, followed by BV, QV and lastly the RV in all the forecast evaluation measurements. The ranking for MSE, MAE and HMSE are consistent for the four models, with TV ranked-1 ${ }^{\text {st }}, \mathrm{BV}$ and $\mathrm{QV}$ as 2 nd and 3 rd and the 4th is RV. This consistency is similar to the definition of robustness by Patton (2011) where the ranking is consistent no matter what type of proxies are used in the evaluations.

To conclude this study, we have conducted a valueat-risk measurement (Jorion 2006) for a one-day horizon forecast using the tripower variation (TV) volatility specification. In order to determine the $\mathrm{VaR}$, one needs the forecasted return and the parametric distribution assumption of the return. For this illustration, we have fitted normal and student- $t$ distributions (degree of freedom $v=$ 5.704675 ) to the return series. Based on the HARX(TV)-GJRGARCH skewed- $t$ model, the long position single market $q \%$ quantile VaR of one-day horizon is $\operatorname{VaR}_{\text {student }-t}(1)=$ capital $\times\left(\hat{r}_{t}(1)+t_{v} \times \sqrt{\widehat{T V}_{t}(1)}\right)$, where $t_{v}$ and $\widehat{T V}_{t}$ represent the $p$ - $t h$ quantile of a student-t distribution with tail parameter $v$, and the forecasted volatility for tripower variation, respectively. For long position investors, they buy a stock, hold it while it appreciates and eventually sell it for profit. They encounter risk when the price of the stock decreases. Thus, long financial position investor concerns about the left tail distribution of the asset return. For comparison, we also computed the normally distributed VaR with the similar derivation $\operatorname{VaR}_{\text {NORMAL,t }}(1)=$ capital $\times\left(\hat{r}_{t}(1)+Z_{\alpha} \times \sqrt{\widehat{T V}_{t}(1)}\right)$. For example, suppose that an investor holds a long position of S\&P 500 with a capital of $\$ 1$ million. The $1 \%$ quantile for one-day ahead for both the normal and skewed- $t$ distributed return series are as computed as follows:

$$
\begin{aligned}
& \text { quantile }_{\text {NORMAL, } 1.0 \%}=0.0007243-2.326348 \times \sqrt{1.94351 \times 10^{-5}} \\
& = \\
& \text { quantile }_{t, 1.0 \%}=0.00009435-3.36493 \times \sqrt{1.90074 \times 10^{-5}} \\
& =-0.013727 .
\end{aligned}
$$

It is understood that the negative sign signifies a loss which located at the left tail distribution. For normally 
distributed returns, the VaR with probability 0.01 is $0.010256 \times \$ 1,000,000=\$ 9531$ whereas the VaR for student- $t$ return recorded a loss of $\$ 13727$. These results showed that with probability $99 \%$, the potential loss of holding this position for the next day (1 day horizon) is $\$ 9531$ and $\$ 13727$ for both the series. It can also be found that the assumption of normally distributed returns has encountered the issue of underestimating VaR.

\section{CONCLUSION}

This study introduced HARX-GJR-GARCH skewed- $t$ model in estimating and forecasting multipower realized volatility for the S\&P 500 index. The multipower realized volatility, namely the Bipower, Tripower and Quadpower realized volatility are robust to abrupt-jump in the financial time-series. In the in-sample forecast, the negative relationship between various realized volatility and its volatility are captured by the GJR-GARCH specification. It is also been shown that the various realized volatility are heavy tailed and slightly skewed to the right under the skewed student- $t$ distribution fitting. The empirical findings found that there is a significant improvement under the three information criteria model selections for the BV, TV and QV specifications. Similar in out-of-sample forecasts evaluations, the $\mathrm{BV}, \mathrm{TV}$ and $\mathrm{QV}$ is superior to the RV specification in four error measurements. As a conclusion, this study provides an alternative approach to deal with high volatile market's volatility forecast as well as market risk determination. In addition, the usage of various realized volatility in this analysis can provides better accuracy in the market risk and portfolio hedging determination for single or multi-assets investment.

\section{REFERENCES}

Andersen, T.G., Bollerslev, T. \& Diebold, F.X. 2006. Roughing it up: Including jump components in the measurement, modeling and forecasting of return volatility. Review of Economics and Statistics 89: 701-720.

Andersen, T. \& Bollerslev, T. 1998. Answering the skeptics: Yes, standard volatility models do provide accurate forecasts. International Economic Review 39: 885-906.

Barndorff-Nielsen, O.E., Graversen, S.E., Jacod, J., Podolskij, M. \& Shephard, N. 2006. A central limit theorem for realised power and bipower variations of continuous semimartingales. Journal of Financial Econometrics 2(1): 1-37.

Barndorff-Nielsen, O.E. \& Shephard, N. 2002. Estimating quadratic variation using realised volatility. Journal of Applied Econometrics 17: 457-477.

Barndorff-Nielsen, O.E. \& Shephard, N. 2004. Power and bipower variation with stochastic volatility and jumps. Journal of Financial Econometrics 2(1): 1-37.

Bollerslev, T. \& Ghysels, E. 1996. Periodic autoregressive conditional heteroscedasticity. Journal of Business \& Economic 14(2): 139-151.

Cervelló, R.R., Guijarro, F. \& Michniuk, K. 2015. Stock market trading rule based on pattern recognition and technical analysis: Forecasting the DJIA index with intraday data. Expert System and Application 42(14): 5963-5975.
Cheong, C.W., Lee, M.C. \& Grace Yap, L.C. 2016 a. Heterogeneous autoregressive model with structural break using nearest neighbor truncation volatility estimators for DAX. SpringerPlus 5(1883): 1-13.

Cheong, C.W., Lee, M.C. \& Grace Yap, L.C. 2016b. Modelling financial market volatility using asymmetric-skewedARFIMAX and -HARX models. Inžinerine Ekonomika 27(4): 373-381.

Cheong, C.W. 2013. The computational of stock market volatility from the perspective of heterogeneous market hypothesis. Economic Computation and Economic Cybernetics Studies and Research 47(2): 247-260.

Corsi, F. 2009. A simple approximate long memory model of realized volatility. Journal of Financial Econometrics 7: 174-196.

Corsi, R., Mittnik, S., Pigorsch, C. \& Pigorsch, U. 2008. The volatility of realized volatility. Econometric Reviews 27: 46-78.

Dacorogna, M., Ulrich, M., Richard, O. \& Oliveier, P. 2001. Defining efficiency in heterogeneous markets. Quantitative Finance 1: 198-201.

Degiannakis, S. \& Floros, C. 2013. Modeling. CAC40 volatility using ultra-high frequency data. Research in International Business and Finance 28: 68-81.

Fama, E. 1998. Market efficiency, long-term returns, and behavioral finance. Journal of Financial Economics 49: 283-306.

Glosten,L.R., Jaganathan, R. \& Runkle, D. 1993. On the relation between the expected value and the volatility of the nominal excess return on stocks. The Journal of Finance 8: 1779-1801.

Hong, Y., Li, H. \& Zhao, F. 2004. Out-of-sample performance of discrete-time spot interest rate models. Journal of Business \& Economic Statistics 22(4): 457-473.

Inkaya, Y. \& Oku, Y. 2014. Analysis of volatility feedback and leverage effects on the ISE30 index using high frequency data. Journal of Computational and Applied Mathematics 259: 377-384.

Jorion, P. 2006. Value-at-Risk: The New Benchmark for Controlling Market Risk. 3rd ed. Chicago: McGraw-Hill.

Lambert, P. \& Laurent, S. 2001. Modelling financial time Series Using GARCH-Type models and a skewed student density. Mimeo, Universitie de Lirege.

Malkiel, B.G. 2003. The efficient market hypothesis and its critics. The Journal of Economic Perspectives 17(1): 59-82.

Muller, U., Dacorogna, M., Dav, R., Olsen, R., Pictet, O. \& Ward, J. 1993. Fractals and intrinsic time - a challenge to econometricians. XXXIX-th International AEA Conference on Real Time Econometrics. pp. 14-15.

Patton, A.J. 2011. Volatility forecast comparison using imperfect volatility proxies. Journal of Econometrics 160(1): 246-256.

Wang, X., Wu, C.\& Xu, W.2015. Volatility forecasting: The role of lunch-break returns, overnight returns, trading volume and leverage effects. International Journal of Forecasting 31: 609-619.

$\mathrm{Zu}$, Y. \& Boswijk, H.P. 2014. Estimating spot volatility with high frequency financial data. Journal of Econometrics 181(2): 117-135.

Chin Wen Cheong* \& Nadira Mohamed Isa Faculty of Management, Multimedia University 63100 Cyberjaya, Selangor Darul Ehsan Malaysia 


\section{Lee Min Cherng}

Lee Kong Chian Faculty of Engineering and Science

Universiti Tunku Abdul Rahman, Sungai Long Campus

Jalan Sungai Long, Bandar Sungai Long

43000 Kajang, Selangor Darul Ehsan

Malaysia

Nadira Mohamed Isa

Faculty of Science and Technology

Universiti Kebangsaan Malaysia

43600 UKM Bangi, Selangor Darul Ehsan

Malaysia
Poo Kuan Hoong

The Nielsen Company (M) Sdn. Bhd.

46100 Petaling Jaya, Selangor Darul Ehsan

Malaysia

*Corresponding author; email: wcchin@mmu.edu.my

Received: 8 October 2015

Accepted: 25 April 2016 